\title{
Using the National Longitudinal Surveys of Youth (NLSY) to Conduct Life Course Analyses
}

\author{
Elizabeth C. Cooksey
}

\section{Introduction}

The National Longitudinal Surveys of Youth (NLSY) include two separate youth cohorts in the United States: the NLSY79 that started in 1979 and the NLSY97 that began in 1997. Each is a nationally representative, longitudinal study with high response rates and frequent follow-ups. Also under the NLSY family of studies are the NLSY79 Child and Young Adult surveys, which follow all children born to female NLSY79 respondents. Data from the NLSY are used by researchers from a wide variety of disciplines including sociology, economics, geography, public health, nursing, psychology, statistics, education, maternal and child health, public policy, and political science. Data are free and easy to access and have also been utilized in cross-national research and policy studies.

Another indicator of the importance of the NLSY is the number of publications written by researchers. As of August 2015, 2892 articles, 188 book chapters, and 131 monographs were

E.C. Cooksey $(\bowtie)$

Center for Human Resource Research, The Ohio State University, Suite 200, 921 Chatham Lane, Columbus, OH 43221, USA

e-mail: Cooksey.1@osu.edu listed in the NLS bibliography as using at least one of the three NLSY surveys, along with 862 $\mathrm{PhD}$ dissertations. In 2014 there were 2250 registered users who downloaded NLSY data, and many others did so as non-registered guests.

In this chapter I begin with a brief history of the National Longitudinal Surveys. I then provide more in-depth information on the three NLSY surveys: the NLSY79, the NLSY79 Child and Young Adult Surveys, and the NLSY97. Next I illustrate some of the ways in which the NLSY provides unique opportunities for researchers. I then present an overview of information pertaining to health that is available in each of the surveys and highlight some of the health-related life course research that has been undertaken using one or more of the NLSY datasets. I conclude with information on how NLSY data may be obtained.

\section{A Brief History of the NLS: The Original Cohorts}

2016 marked the 50th anniversary of the first National Longitudinal Survey (NLS) interview and 50 years of involvement in the NLS project by the Center for Human Resource Research (CHRR) at The Ohio State University. Sponsored by the US Department of Labor, the first cohort of Older Men consisted of 5020 males born 
between 1906 and 1921 who were ages 45-59 when first interviewed by the Census Bureau in 1966. This cohort was selected to enable research on the employment patterns of men as they neared the completion of their careers and answer questions regarding their plans for retirement. An oversample of black respondents was included, and 13 interviews were conducted over a span of 24 years. A total of 2092 Older Men were interviewed in 1990 when they were ages 71-83 years old, and interviews were also conducted with 2206 widows or other family members of deceased respondents. Although primarily focused on aspects of employment income and retirement, the survey also collected information on health and physical condition.

The NLS of Young Men, a sample of 5225 males born between 1941 and 1952, was also started in 1966 when they were 14-24 years old. The Young Men's cohort chronicled the employment patterns of men transitioning from school and into the work force or joining the military, i.e., making initial career and job decisions that would impact their employment in the decades to follow. Twelve interviews were conducted between 1966 and 1981 when the study ended. As with the Older Men, young black men were oversampled, and information was collected on health and physical condition.

The following year, 1967, a sample of 5083 Mature Women born between 1922 and 1937 was drawn to study the return of women to the labor force as their children grew up, and to investigate how women balanced the roles of homemaker, mother, and labor force participant. A total of 22 surveys were undertaken with these women, with their first interview at ages 30-44 and their last interview in 2003, at ages 63-77. Finally, in 1968, 5159 Young Women were interviewed at ages 14-24 as they were completing school, making career and job decisions, and starting families. Twenty-two interviews were undertaken with the Young Women's cohort, ending in 2003. As with both Original Cohorts of males, the two cohorts of female respondents again included oversamples of blacks and survey questions on health and physical condition.

\section{The National Longitudinal Surveys of Youth}

The NLSY79 originally comprised a sample of 12,686 men and women born between 1957 and 1964 who were living in the United States when the survey began. When first interviewed in 1979, they were ages 14-22 years. This time CHRR partnered with the National Opinion Research Center (NORC) to undertake the fielding of the survey, which was conducted primarily with funds from the Bureau of Labor Statistics at the US Department of Labor, although other agencies provided funding for various purposes. For example, the National Institute of Child Health and Human Development (NICHD) has supported the collection of a wide range of data in the NLSY79, including marriage and fertility histories for all respondents as well as comprehensive pre- and postnatal data relating to each child born to female NLSY79 respondents and information pertaining to child health and childcare from the early survey years. The Armed Services Vocational Aptitude Battery (ASVAB) was administered to both the civilian and military youth samples interviewed in $1980(N=11,914)$ with sponsorship from the Department of Defense (DoD). These data include respondent raw scores, standard scores, scale scores, and standard errors for each of the ten test sections, including general science, arithmetic reasoning, work knowledge, mechanical comprehension, and two constructed Armed Forces Qualifications Test (AFQT) scores. The AFQT has been shown to be a significant predictor of later life course outcomes across a whole range of social, economic, educational, and health domains. Support from the DoD also made possible the 1979-1984 interviews of 1280 youth enlisted in the military.

Beginning in 1979, a 5-year collaborative effort between CHRR and the National Center for Research in Vocational Education resulted in a survey of the high schools civilian NLSY79 respondents attended, along with the collection of detailed transcript information, for 8778 NLSY79 respondents expected to complete high school during the 1980-1983 survey years. 
Information on up to 64 high school courses, including course descriptions, final grades, and credit received, was collected. Moreover, data were gathered from the record of the last secondary school attended by the NLSY79 respondents. These variables include both respondent-specific and school-specific information on such factors as (a) the respondent's school enrollment status, highest grade attended, remedial classes taken, and scores/percentiles/grade levels for various intelligence and aptitude tests administered during the youth's schooling and (b) each school's total enrollment, grading system, types of curricula offered, dropout rate, student body composition, and staffing characteristics. In addition, the National Institute of Education sponsored a set of time-use questions in 1981, and a self-report supplement to the 1980 survey was funded by the US Department of Justice to collect data on respondents' participation in, and income from, various delinquent and criminal activities. Lastly, funding from the National Institute on Alcohol Abuse and Alcoholism and the National Institute on Drug Abuse has made possible expanded sets of alcohol and substance use questions.

The NLSY79 cohort was selected to replicate the NLS of Young Women and Young Men cohorts and was also designed to help researchers and policymakers evaluate the expanded employment and training programs for youths legislated by the 1977 amendments to the Comprehensive Employment and Training Act. Survey respondents have been interviewed every year through 1994 and every other year since then. The 2014/2015 survey marked the 26th round of data collection, with respondents ages 50-58 at the start of the round.

Interviews are conducted either face to face or by telephone, with telephone mode increasing with each subsequent round as respondents have become more geographically dispersed or expressed a preference for phone interviews. In recent rounds more than $90 \%$ have been conducted by telephone.

The initial sample of 12,686 youth interviewed in 1979 comprised a cross-sectional sample of 6111 respondents designed to represent the noninstitutionalized civilian segment of people living in the United States in 1979 and born between January 1, 1957, and December 31, 1964, along with a supplemental sample of 5295 civilian Hispanic or Latino/Latina, black, and economically disadvantaged nonblack/non-Hispanic respondents of the same ages. Also included was a sample of 1280 respondents designed to represent the population serving in one of the four branches of the US military as of September 30, 1978, who were born between January 1, 1957, and December 31, 1961, and who were therefore ages 17-21 as of December 31, 1978. The initial sample was evenly divided by gender and had 7510 nonblack/non-Hispanic respondents, 3174 black respondents, and 2002 Hispanic or Latino/ Latina respondents. Due to budget constraints, 1079 members of the supplemental sample of armed forces youth were discontinued after the 1984 survey, and the economically disadvantaged nonblack/non-Hispanic supplemental sample of 1643 individuals was discontinued after 1990. In Round 25 (completed in 2013), over 80\% of respondents in the remaining sample types were interviewed; of these respondents, $69 \%$ had answered every survey round since 1979 with a further $14 \%$ answering all but one.

The oversamples of black and Hispanic respondents and the fact that data have been collected either every year or every other year from the same set of people over such a long period of time, so many of them answering questions at 24 or more separate survey points, make the NLSY79 a remarkable panel study of individuals ideally suited for life course studies. Beginning in their teenage years, these individuals were followed as they left secondary school, entered college or training programs, moved into their first jobs, moved in with partners, got married, had children (although not necessarily in that order), lost jobs, changed jobs, had more children, bought and sold houses, progressed into middle age, began to think that they might like to retire one day, and paid into pension plans. And throughout these years, NLSY79 respondents answered not only questions about work, marriage, and family activities but also about beliefs, hopes, and expectations for the future, mental and physical health, alcohol and drug use, and 
sexual activity and contraceptive use. Although at its heart the NLSY79 remains a labor survey, its breadth of topics covered ensures that the nuances of people's work lives can be placed into the much larger context within which people actually live their lives. And as I describe later, the NLSY79 has also collected information on a host of healthy and unhealthy behaviors and a range of mental and physical health antecedents and outcomes that are not only important in terms of people's work lives but provide unique opportunities for health researchers who wish to study health over the life course.

Although the NLSY79 is a survey of individuals rather than a survey of households, respondents interviewed in 1979 originated from 8770 unique households out of which 2862 households included more than one NLSY79 respondent. The most common relationships between respondents living in multiple respondent households at this time were those of sibling or spouse: 5863 respondents were members of a household containing multiple interviewed siblings (biological, step, or adopted), and 334 respondents were members of a household in which their spouse was also interviewed (see Table 1).

The NLSY79 Child and Young Adult Surveys The NLSY79 Child study began in 1986 with funding from NICHD; at that time there were 5255 children reported by 2922 interviewed mothers. Designed to obtain comprehensive information on the experiences of children born to female NLSY79 respondents, a battery of cognitive, socioemotional, and physiological assessments has been administered biennially to all children of

Table 1 Number of NLSY79 civilian respondents by type of single/multiple sibling household, 1979

\begin{tabular}{l|l|l}
\hline Type of household & $\begin{array}{l}\text { Number of } \\
\text { respondents }\end{array}$ & $\begin{array}{l}\text { Number of } \\
\text { households }\end{array}$ \\
\hline Single respondent & 5908 & 5908 \\
\hline Multiple siblings & \multicolumn{2}{|l}{} \\
\hline Two siblings & 3386 & 1693 \\
\hline Three siblings & 1725 & 575 \\
\hline Four siblings & 604 & 151 \\
\hline Five siblings & 130 & 26 \\
\hline Six siblings & 18 & 3 \\
\hline Total multiple siblings & $\mathbf{5 8 6 3}$ & $\mathbf{2 4 4 8}$ \\
\hline
\end{tabular}

selected ages through 1992 and to children below the age of 15 since 1994. Some of these assessments directly assess each child's development using nationally normed tests such as the Peabody Picture Vocabulary Test-Revised (PPVT-R) which measures a child's hearing vocabulary; the Digit Span subscale of the Wechsler Intelligence Scale for Children-Revised (WISC-R) which measures short-term memory (Wechsler 1974); the Peabody Individual Achievement Test (PIAT): math, reading recognition, and reading comprehension assessments which measure ability in mathematics, oral reading, and the ability to derive meaning from printed words (Dunn and Dunn 1981); and Harter's Self-Perception Profile for Children (SPPC) that measures a child's perceived competence in academics and sense of general self-worth (Harter 1985). Although all of these tests have been administered to children of the NLSY79 biennially, the ages at which they were given have sometimes changed, and users of the data are advised to check the user's guide at https://www. nlsinfo.org. As shown in Table 2, other tests such as the McCarthy Scale of Children's Abilities: Verbal Memory subscale, Memory for Location Assessment, and Body Parts Assessment were only administered in early rounds of the survey.

The number of children assessed during a given child survey year is a function of the number of children born to interviewed NLSY79 mothers, the number of children living in the homes of those mothers, and, finally, the number of those children actually interviewed. Of the 5842 NLSY79 females eligible for the first child interview in 1986, 2922 mothers and 4971 children were interviewed. From this sample of eligible children, assessment data were collected for 4786 of them.

Each mother also provides reports on her children's temperament, motor and social development, behavior problems, and home environment. Three age-specific versions of the temperament scale assess such factors as activity, predictability, positive affect, fearfulness, compliance, and insecure attachment among young children; the motor and social development scale measures milestones in the areas of motor, cognitive, communication, and social development for children 
Table 2 Child assessments by year of survey

\begin{tabular}{l|l|l|l|l|l|l}
\hline Child assessment & 1986 & 1988 & 1990 & 1992 & 1994 & $1996-2014$ \\
\hline $\begin{array}{l}\text { Parts of the body: number of body parts child can identify by } \\
\text { common names }\end{array}$ & $*$ & $*$ & & & & \\
\hline Memory for locations: how long child remembers the location of the doll & $*$ & $*$ & & & & \\
\hline Verbal memory test: ability to remember and repeat word sequences & $*$ & $*$ & $*$ & $*$ & $*$ & \\
\hline Peabody Picture Vocabulary Test (PPVT) & $*$ & $*$ & $*$ & $*$ & $*$ & $*$ \\
\hline Memory for Digit Span test (WISC-R): memory for number order & $*$ & $*$ & $*$ & $*$ & $*$ & $*$ \\
\hline PIAT math subtest & $*$ & $*$ & $*$ & $*$ & $*$ & $*$ \\
\hline PIAT reading: recognition and comprehension subtests & $*$ & $*$ & $*$ & $*$ & $*$ & $*$ \\
\hline SPPC: what child thinks he or she is like, how he or she thinks and feels & $*$ & $*$ & $*$ & $*$ & $*$ & $*$ \\
\hline Temperament scales & $*$ & $*$ & $*$ & $*$ & $*$ & $*$ \\
\hline $\begin{array}{l}\text { Motor and social development scale } \\
\text { (not administered in 2004) }\end{array}$ & $*$ & $*$ & $*$ & $*$ & $*$ & $*$ \\
\hline Behavior problems index & $*$ & $*$ & $*$ & $*$ & $*$ & $*$ \\
\hline Interviewer evaluation of testing conditions & $*$ & $*$ & $*$ & $*$ & $*$ & $*$ \\
\hline HOME-SF inventory & $*$ & $*$ & $*$ & $*$ & $*$ & $*$
\end{tabular}

* Signifies that those questions were asked in that particular survey round

under age four; and one of the most widely used scales in research on children using the NLSY79 is the Behavior Problems Index (BPI) which is completed for all children ages four and over. The BPI consists of an overall behavior problem score that is comprised of six subscales (antisocial, anxious or depressed, hyperactive, headstrong, dependent, and peer conflicts), and individual items may also be classified as internality and externality scales. Interviewer assessments of children's shyness, cooperation, interest, and persistence during the interview, as well as their attitude about and rapport with the interviewer, are also collected. The final measure in Table 2, the Home Observation Measurement of the Environment-Short Form (HOME-SF), is a modification of the HOME inventory (Caldwell and Bradley 1984) and is a unique measure of the quality of the cognitive stimulation and emotional support provided by a child's family. This measure has also been extensively used in research as both an input in helping to explain other child characteristics or behaviors and as an outcome to explain associations between the quality of a child's home environment and earlier familial and maternal traits and behaviors.

The NLSY79 Child surveys have also gathered substantial information about the educational experiences of each child. Mothers have provided information about preschool and regu- lar school attendance, type of school attended, grades skipped or repeated, and how well the child performs in class. Since 1988, children ages 10 and over have supplied information on characteristics of their school, the involvement of their parents in their education, and their educational expectations. In 1995-1996 a one-time school survey - funded by a grant through the National Institute of Child Health and Human Development - was conducted to collect information from school officials at schools attended by NLSY79 child respondents in grades 1 through 12 during either the 1993-1994 or 19941995 school year. This effort gathered information about the characteristics of the school and standardized test scores recorded from student transcripts.

Each child survey from 1988 onward has also collected self-reported information from children age 10 and older about child-parent interactions, responsibilities at home, attitudes toward school, time use, employment, religious attendance, alcohol and drug use, sexual activity (at age 13 and older), dating and friendship patterns, and various other attitudes and behaviors.

In 1994, the NLSY79 data collection was again expanded to incorporate extensive interviews with NLSY79 Young Adults. This is not a new cohort but rather what NLSY79 Children are called when they turn age 15 (technically, the 
young adult sample is defined as children who have their 15th birthday in the year they are interviewed; thus, some of them are still age 14 when interviewed as young adults). In 1994, 6109 children under age 15 and 980 young adults reported by 3464 mothers were interviewed. In 1994 and 1996, the young adult data collection effort was part and parcel of the child data collection effort under a contract with the US Department of Labor with funds provided by NICHD. In 1998, because of funding constraints, interviews were limited to young adults under age 21. Since 2000, however, CHRR has obtained separate funds through the NICHD grant process to continue to interview young adults aged 21 and over and hence expand the analytical value of these data. All young adults ages 15-30 are interviewed biennially, and after age 30, they are interviewed every other survey round or roughly every 4 years.

In 1994, 1996, and 1998, the interviews were mainly conducted in person and included two parts. First was a computer-assisted personal interview that largely paralleled the main NLSY79 data collection but with a greater focus on youth issues. This included detailed employment, education, and family/relationship profiles, income, training, military service, and attitudinal measures and assessments such as the Rosenberg Self-Esteem Scale and the CESD depression scale. Second, young adults completed a confidential self-report questionnaire which focused on more sensitive issues including sexual activity, contraception, expectations for the future, dating and relationship experiences, political attitudes, pro-social behaviors, substance use, and risk-taking attitudes.

Other questions continued or were parallel to questions from the Child survey such as data on routine health checks, accidents and injuries, dating behaviors, the respondent's relationship with his or her parents, risk-taking behaviors, and school experiences and satisfaction.

The 2000 and later data collection efforts shifted to focus more heavily on recent mainstream employment and family experiences for the older grant-age young adults, many of whom had completed their schooling. Examples of more tailored questions for this older age group include the timing of and reasons for leaving home, the contact young adults had with their parents when they left home, their marriage and cohabitation histories, and (as they entered parenthood) the different kinds of childcare facilities they used and how much their childcare arrangements cost. In 2004 a series of questions on asthma was added, and the Ten-Item Personality Inventory (TIPI) was included in 2006. In 2008 the survey incorporated a six-item anger scale and questions on whether or not respondents had seen action in combat zones, with whom their biological children lived at the time of their birth, and more details about healthy activities. Also, building from qualitative research done by Wendy Manning and Pamela Smock (2005), new questions were designed to get a better handle on the types of relationships and dating activities that youth engaged in during their teens and twenties. Additional health-related questions were included between 2010 and 2014 and these are described in more detail in the health section.

At the start of the 2014 field period for round 26 of the NLSY79, female respondents were ages 50-57 and had essentially completed their fertility. At this time a total of 11,512 children were known to have been born to the original 6283 NLSY79 female respondents. Most of these births occurred during the years this cohort has been interviewed although a modest number of children were born prior to 1979. An unknown number of additional children will have been born to women who have left the survey (mostly as a result of being part of the economically disadvantaged oversample that was dropped after 1990) subsequent to their attrition. Fifty-one percent are sons and $49 \%$ are daughters, and based on the race/ethnicity of their mothers, $53 \%$ would be classified as nonblack/non-Hispanic, $28 \%$ as black, and $19 \%$ as Hispanic. The oldest child was born in 1970 to a teenage mother. The youngest child was born in 2011 to a mother in the older childbearing years. At the time of the first interview in 1986, child ages ranged from 0 to 15 years of age. In 2014/2015 NLSY79 Children were 0-14 years old and Young Adults were ages 
14-44 years. Finally, retention rates have again been very high: at the end of fielding in 2013, $81 \%$ of young adults and $90 \%$ of children eligible to be fielded during this survey round had been interviewed. Of these respondents, close to $77 \%$ of young adults had been interviewed either every time or all but once which translates into 13 or 14 different data points over a 28 -year period.

The NLSY97 is the newest survey in the NLS program and comprises a sample of 8984 young men and women born between 1980 and 1984 who were ages $12-17$ when first interviewed in 1997. As with the NLSY79, the NLSY97 also had a cross-sectional sample of respondents designed to be representative of people at those ages and living in the United States at the time $(N=6748)$ and a supplemental sample of 2236 black and Hispanic respondents, which resulted in a total sample that was $52 \%$ nonblack/nonHispanic, $26 \%$ black, $21 \%$ Hispanic or Latino/ Latina, and just under $1 \%$ mixed race. Because all household residents in the appropriate age range were selected, again some households included more than one NLSY97 respondent, the most common relationship being that of siblings. The original sample in 1997 was 51\% male and $49 \%$ female.

CHRR and NORC again partnered to undertake the study which was also primarily funded by the BLS. Other agencies have contributed to the project over the years, however. For example, in Round 1, a computer adaptive version of the Armed Services Vocational Aptitude Battery (ASVAB) was given to NLSY97 respondents with sponsorship by the Department of Defense. Various questions in the self-administered portion of the questionnaire, including questions on health, fertility, and social relationships, have been funded by the NICHD. School surveys were undertaken in 1996 and 2000 to collect information from all high schools with a 12th grade in the 147 NLSY97 primary sampling units as well as the collection and coding of high school transcripts, and this work was funded by the Department of Education. Questions on crime and criminal activities have been sponsored by the Department of Justice, Office of Juvenile Justice and Delinquency Prevention.
The NLSY97 cohort was designed to enable research on youths' transition from school to the labor market and into adulthood for a generation born into a very different time period than youth in the " 79 cohort who had transitioned into adulthood during the 1980s: NLSY79 respondents are younger baby boomers, whereas NLSY97 respondents are the oldest of the millennial generation. These two cohorts have moved into early adulthood under very different educational, employment, and family building circumstances. Current population survey time trend data (www. census.gov/hhes/socdemo/education/data/cps/ historical/index.html) show that in 1990, when the youngest NLSY79 cohort member was 25, the percentages of youth ages 25 and over who had completed high school or college were $23.7 \%$ for men and $22.8 \%$ for women. In 2009 when the youngest member of the NLSY97 cohort was age 25 , the percentage for males had increased only slightly to $26.6 \%$, but for women, the rise was substantial to $34.8 \%$. Based on figures from the March 2013 current population survey, 38\% of older millennial females ages $25-32$ had a bachelor's degree. The corresponding figure for their male counterparts was $31 \%$. Higher education has become increasingly important for successful labor force participation for millennials. According to a report from the Pew Research Center (2013), women accounted for $43 \%$ of the US labor force in 1980, and this rose to $47 \%$ in 2012. Among young women (ages 25-34), 74\% were in the labor force in 2012, up from $66 \%$ in 1980. Labor force participation among men on the other hand has declined over the past 30 years, from $78 \%$ in 1980 to $70 \%$ in 2012 . Furthermore, each new wave of adult men younger than age 35 has been less active in the labor market than the preceding wave. Living arrangements have also changed over time. For example, in 1987 when NLSY79 respondents were ages 22-29 years old, the percentage of 25-29-year-olds who had ever cohabited was 41\%. In 2009-2010 when NLSY97 cohort members were 25-30, this percentage had risen to $66 \%$ (Bumpass and Sweet 1989; Bumpass and Lu 2000; Kennedy and Bumpass 2008). 
The NLSY97 cohort is also ongoing and has been surveyed every year from 1997 through 2011 and biennially since. In 2015, 16 survey rounds had been completed and respondents were ages 28-34. Up until 2015, data collection has been primarily via in-person interviewing. Beginning in round 18 , set to start in late fall of 2017 , there will be a shift to mostly phone interviewing. As with the NLSY79 and the NLSY79 Child and Young Adult surveys, oversamples of black and Hispanic respondents, very high retention rates, and the fact that the same people have been interviewed so frequently make the NLSY97 another remarkable panel that is highly appropriate for longitudinal and life course studies, especially during the life course stages from adolescence through early adulthood when frequent education, employment, fertility, and living arrangement transitions occur. And again, response rates have been exceedingly high: in Round 16 which was completed in 2014, $81 \%$ of respondents not known to be deceased were interviewed. Of these interviewed respondents, $69.5 \%$ had answered all 16 surveys since 1997 , and a further $12 \%$ had answered 15 of them.

\section{The Uniqueness of the NLSY}

Many factors make the NLSY datasets a unique source of data for researchers interested in studying the life course. First, there have been many rounds of data collection at very frequent intervals: NLSY79 respondents have been interviewed up to 26 times between when they were teens in 1979 and their late forties to mid-fifties in 2015; children born to NLSY79 females have been assessed and interviewed up to 15 times, most of them from birth onward; and NLSY97 respondents have been interviewed up to 16 times from their early to mid-teens into their thirties. Such a wealth of data can seem overwhelming at times, but they also lend themselves to a better understanding of important life course trajectories and how change in one area of life can lead to both short-term and longer-term change in other realms.

The length of time that these studies have been ongoing, and the extraordinarily high response rates achieved from so many individuals who have been prepared to share of their lives round after round, means that researchers can explore potential consequences of events that happen at early stages in the life course many years later, while still being able to account for a broad array of occurrences in the intervening years. In 2004, Hayward and Gorman published a paper in Demography titled "The Long Arm of Childhood: The Influence of Early-Life Social Conditions on Men's Mortality" in which they drew on the NLS Older Men's cohort to study links between various childhood conditions and mortality in adulthood. Although they had to rely on retrospective reports from men in their forties and fifties about their childhood years, their results showed that men's mortality was indeed associated with an array of childhood conditions including socioeconomic status, family living arrangements, mother's work status, rural residence, and parents' nativity. With information from multiple interviews to draw from, they were then able to demonstrate how, with the exception of parental nativity, these associations were mediated by various lifestyle factors, particularly body mass and socioeconomic achievement processes in adulthood. They concluded that their findings highlighted the idea that economic and educational policies targeted at children's well-being are implicitly health policies with effects that reach far into the adult life course. As the NLSY79 cohort ages into their retirement years and beyond, it will be possible to replicate this research with prospective rather than retrospective data, and the NLSY79 Child and Young Adult data will enable researchers to go back to the earliest years of childhood and even include prenatal conditions as reported by mothers.

The United States does not have birth cohort studies as other countries, such as the United Kingdom, do. However, data on the children of the NLSY79 do provide information on children from birth. With input from child development experts, the child study was designed to gather information from their mothers during infancy and early childhood, to assess children in their elementary and middle school years and to interview them from middle school onward into adolescence and adulthood.

As illustrated in Fig. 1 below, given the wealth of data that have been collected on these children 
Fig. 1 Research possibilities using the NLSY79 Child and Young Adult data

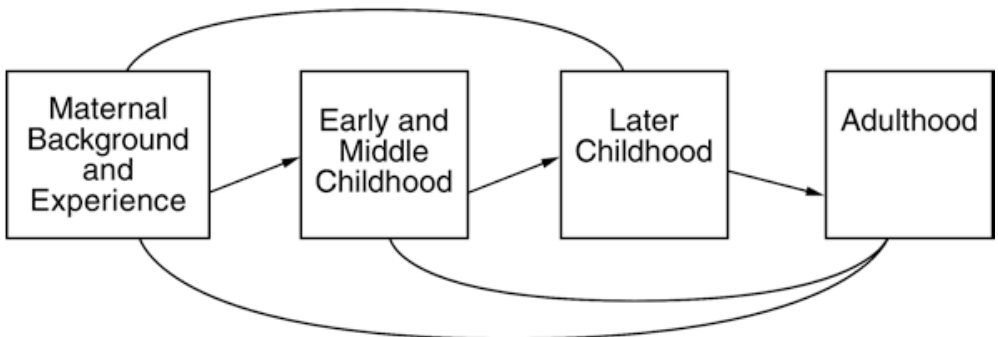

Fig. 2 Crossgenerational research possibilities using the NLSY79 Maternal, Child, and Young Adult data

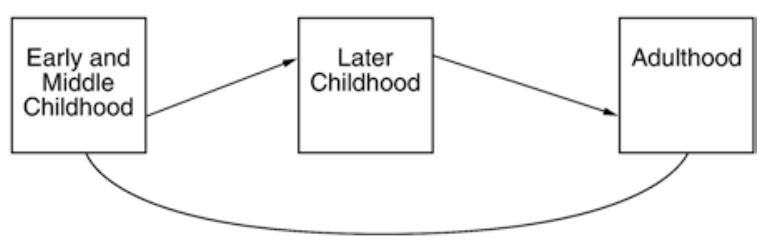

care in the first year of life. NLSY79 mothers also provide prenatal information for all births including data on their use of prenatal care, alcohol, cigarettes, marijuana, cocaine and dietary supplements and whether they had sonograms or amniocentesis during pregnancy.

As shown in Fig. 2, the availability of comprehensive child data, coupled with a wealth of longitudinal information on the background, and well-being of their NLSY79 mothers, provide researchers with a unique opportunity to undertake intergenerational research and examine linkages between maternal family behaviors and attitudes on the one hand and multiple aspects of their children's development on the other hand.

As an example, one might be interested not only in how deviancy develops from childhood into the young adult years but also in how the evolution of deviant behaviors might relate to behaviors and experiences in the prior generation-in this case among the youths' mothers. Further, as mentioned earlier, not only are similar data collected from both mothers and their children but retrospective reporting need not be relied on to link maternal reports of behaviors with those of their child, since data were collected from the NLSY79 mothers on their behaviors at, for example, ages 16 or 18 when they were 16 or 18 , and then again from their children when they were 16 or 18 years old. The fact that many questions were asked of NLSY79 females and of their as breastfeeding practices, other infant feeding
practices, illnesses and injuries, and well-baby 
children when they were the same ages makes these data especially distinctive.

The information presented earlier in Table 1 provides another example of how the NLSY79 provides opportunities for life course research in ways not necessarily expected from cohort studies. Because information is collected for all children born to female respondents, and some of those NLSY79 female respondents were themselves sisters, the NLSY79 Child/Young Adult data not only offer opportunities for comparing developmental and other outcome measures between siblings but also between cousins. The relatively large sample of siblings and cousins permits researchers to explore both within- and cross-family effects to a greater extent than is typically possible. Over the course of the survey years, more than 3000 children in the sample have been identified as having an aunt in the NLSY79 main youth sample. Most of these children have one aunt, but there are also some child respondents with multiple aunts. The number of children who are cousins is also considerable.

More typically, researchers have tended to utilize the large number of child sibling sample cases that have been born to the female respondents. As shown in Table 3, 78.5\% of NLSY79 women had at least one child, and most of them have had more than one, including a fairly large sample of women who have had three or more children by the end of their childbearing years. In addition to multiple births, there are many family units where two or more children are widely spaced in age. This enables exploring the impact of childbearing on children born to the same mother at different maternal life cycle stages.

A number of articles published in recent years have used either sibling data from the NLSY79 main youth sample or the Child and Young Adult sample or cousin data from this second generation (see, e.g., D'Onofrio et al. 2008, 2009a, b; Rodgers et al. 2008; Mendle et al. 2009; Jaffe et al. 2011; Goodnight et al. 2012 and Donahue et al. 2014).

Because there is considerable overlap in questions asked of NLSY97 and NLSY79 participants, intergenerational comparisons can be made using information from these two cohorts. Furthermore,
Table 3 NLSY79 women by number of children and race/ethnicity

\begin{tabular}{l|l|l|l|l}
\hline $\begin{array}{l}\text { Number of households } \\
\begin{array}{l}\text { Type of household } \\
\text { female) }\end{array}\end{array}$ & Hispanic & Black & White & Total \\
\hline $\begin{array}{l}\text { Females with no } \\
\text { children }\end{array}$ & $\mathbf{1 5 8}$ & $\mathbf{2 8 5}$ & $\mathbf{9 0 8}$ & 1351 \\
\hline $\begin{array}{l}\text { Mothers with 1 or } \\
\text { more child }\end{array}$ & $\mathbf{8 4 4}$ & $\mathbf{1 2 7 6}$ & $\mathbf{2 8 1 2}$ & $\mathbf{4 9 3 2}$ \\
\hline $\begin{array}{l}\text { Mothers with 1 } \\
\text { child }\end{array}$ & 147 & 278 & 750 & 1175 \\
\hline $\begin{array}{l}\text { Mothers with 2 } \\
\text { children }\end{array}$ & 310 & 457 & 1204 & 1971 \\
\hline $\begin{array}{l}\text { Mothers with 3 } \\
\text { children }\end{array}$ & 222 & 315 & 591 & 1128 \\
\hline $\begin{array}{l}\text { Mothers with 4 or } \\
\text { more children }\end{array}$ & 165 & 226 & 267 & 658 \\
\hline Total & $\mathbf{1 0 0 2}$ & $\mathbf{1 5 6 1}$ & $\mathbf{3 7 2 0}$ & $\mathbf{6 2 8 3}$ \\
\hline
\end{tabular}

a significant number of NLSY79 Young Adults were born in the same years as NLSY97 respondents, and hence members of these two datasets can be compared with each other when overlap of questionnaire design allows. One of the drawbacks of the NLSY79 Young Adult data is that although young adults were born to women who were part of a nationally representative sample of youth living in the United States in 1979, due to immigration and fertility differentials by various background variables (e.g., race/ethnicity), the NLSY79 Young Adults are by no means nationally representative in nature. The NLSY97 respondents are, however, representative of teenagers who were living in the United States in 1997 and hence are a more generalizable sample. Although immigration since 1997 has changed the racial/ethnic makeup of the US population so that NLSY97 respondents are also no longer representative of all Young Adults in their thirties living in the US today, they are still closer than the NLSY79 Young Adults of the same ages.

On the other hand, the NLSY79 Young Adults of comparable age to the NLSY97 respondents have the strong advantage of having been followed since birth, plus in-depth information was gathered from their mothers over many years. Comparisons of research using the Young Adults with research utilizing the NLSY97 can therefore provide insights concerning the importance of 
non-representativeness in the Young Adult sample and potential selectivity bias in the NLSY97 due to the failure to include important prenatal or early childhood information. In other words, the strengths of one dataset can be used to evaluate potential weaknesses in the other.

Lastly, geographic residence information is available in all three datasets and the county and state of residence are provided in a separate restricted-access geocode $\mathrm{CD}$ that can be matched with other data sources to investigate community characteristics and contextual variables.

A number of design decisions make the NLSY97 the preferred choice of dataset to study certain behavioral choices and life events. For example, more in-depth data related to crime and delinquency are available in the NLSY97 than in the NLSY79, and a full cohabitation history also exists in the NLSY97 whereas the information available from NLSY79 respondents does not enable a complete record of living arrangements to be constructed. However, the linked NLSY79 and NLSY79 Child and Young Adult files are more ideally suited for the study of maternal and child health, since NLSY79 women have now aged through their fertile years and detailed information has been collected on all of their biological children. It is therefore the NLSY79 data that I primarily focus on in the next sections of this chapter.

\section{$5 \quad$ Health Data in the NLSY Surveys}

NLSY79 health sections are divided into two periods. Between 1979 and 1996, although the specific questions that were asked varied at times, most questions focused on health concerns that restricted or inhibited the respondent's ability to work. From 1998 on, as respondents reached middle age, the health section was expanded to provide a baseline profile of the respondent's overall health as they turned 40 years old. From 2008 onward, respondents have been asked another set of health questions when they turn 50 .

Although the pre-1998 health questions provide a picture of the respondents' health restrictions at the time of interview, they offer little insight into chronic health problems that might affect their labor force activity in the future. For example, a serious ailment with slow development would not be picked up by the regular health questions until a respondent actually dropped out of the labor market. The extended 40-and-over health module was therefore created to provide a baseline health profile for each respondent to facilitate research of the interrelationship of health and labor market activity in the advancement of retirement ages. Questions are not restricted to work-related health problems, and all questions are asked irrespective of the respondent's labor force status. Full information is available on www.nlsinfo.org but questions include items from the Center for Epidemiological Studies Depression Scale (CES-D), information on when respondents last saw a health care professional, and reports about the health and life status of the NLSY79 respondents' biological parents designed to improve researchers' understanding of hereditary health problems. The module also reproduces the SF-12 scale, a 12-question health survey designed by John Ware of the New England Medical Center Hospital that provides a measure of the respondents' mental and physical health irrespective of their proclivity to use formal health services (Ware et al. 1995). Finally, respondents are asked if they suffer from an extensive list of health conditions including asthma, back problems, problems with their feet and legs, kidney or bladder, stomach or intestinal ulcers, high cholesterol, chest pain, heart trouble, low blood pressure, sinus infections, joint swelling or pain, leg cramps, painful shoulders, elbows or knees, frequent headaches, severe tooth or gum trouble, skin diseases, and thyroid problems.

The 50-and-over health module was included beginning in 2008 at which time the module was administered to respondents born in 1957-1958. In 2010, it was administered to those born in 1959-1960, and anyone who skipped the 2008 interview, and so on. This module contains many of the same questions as the 40-and-over health module. Some questions therefore provide a second decennial point of reference for general health information and many others provide updates on previously reported conditions. 
Questions about diagnosis of skin cancer and other types of cancer, various heart diseaserelated conditions, and stroke were also asked.

50-and-over respondents are again administered the CES-D items and the SF-12 question series, as well as questions about the life and health status of their parents if they were previously reported as living. In addition, 50-and-over respondents update information on previously reported conditions such as hypertension/high blood pressure, diabetes/high blood sugar, asthma and non-asthma breathing problems, depression and other emotional/psychiatric problems, and arthritis. Questions have also been included on diagnosis of osteoporosis and the use of special equipment needed to accomplish usual activities, as well as a scale of functionality and the respondent's sleep habits.

In addition to the two health modules asked around age 40 and around age 50, other health questions have been incorporated into the NLSY79 questionnaire as mini-modules or small groups of questions to capture retrospective accounts of health in the childhood years prior to 1979 , baseline measures of general health and cognition, information on the use of particular medications, and reports of head injuries. For example, in 2012 all respondents were asked a series of new questions on childhood health including overall health, major hospitalizations, or long periods of home recovery. Questions on childhood adversity that dealt with family mental health, alcohol abuse, physical abuse, and amount of parental affection were also added as researchers believe that questions such as these are predictive of adult obesity and other health-related outcomes.

Beginning in 2006, respondents ages 48 and 49 were given a battery of exercises designed to capture cognitive capabilities. Similar to the 50-andover health module, this cognition module has also been administered to progressive 2-year birth year cohorts in the survey year during which they would turn at least age 48. This module solicits the respondent's own assessment of his/her general health, a word recall exercise using randomly assigned sets of ten words, and exercises requiring the respondent to count backward from a starting point by a specified number.

In 2004 a series of questions about asthma were added to the survey, and starting in 2008, respon- dents were asked if they were taking any statin drugs or heart medications. In 2012 all respondents were asked if they had experienced a serious head injury or loss of smell. Because traumatic head injury and loss of smell have been found in numerous studies to be linked to subsequent dementia, these questions were included to augment ongoing efforts to track respondents' cognitive function as they advance through middle age and beyond.

As mentioned in the section above, NLSY79 mothers have also provided a variety of information about their prenatal and postnatal activities relating to each child since 1983. Table 4 below summarizes some of the other health-related data available on children born to NLSY79 mothers and collected since the advent of the child survey in 1986:

Starting in 1996, mothers have additionally been asked to rate their child's health on a 4-point scale from "poor" to "excellent." Detailed information is available in the User's Guide at www. nlsinfo.org/content/cohorts/nlsy79-children/ topical-guide/health.

Health questions continue as children become Young Adults. In some areas, questions closely parallel the health history obtained for all children of NLSY79 mothers (e.g., height and body weight, types of limitations, number of accidents and injuries in the last 12 months, hospitalizations resulting from these accidents/injuries, and insurance coverage). Young Adult respondents who do not live with their mother are also asked about illnesses and routine medical care. For younger Young Adults who do live with their mother, comparable questions are asked of the mother. Items from the CES-D depression scale are also asked of Young Adults in multiple survey rounds.

In 2004, respondents received two new series of questions. The first focused on health-related behaviors such as fruit and vegetable consumption, hours of sleep per night, and level of exercise. The second series was centered on asthma with detailed questions designed to track the onset of asthma and the persistence and severity of related symptoms. This series also includes two questions about whether anyone has smoked cigarettes in the respondent's home in the last 2 weeks and whether the respondent has routinely spent time somewhere in the last 2 weeks where they can smell cigarette smoke. 
Table 4 Health-related data available on children of the NLSY79

\begin{tabular}{|c|c|c|c|c|c|}
\hline Child health & 1986 & $1988-1992$ & 1994 & 1996-2002 & 2004-2012 \\
\hline Rating of child's health & & & & M & M \\
\hline Does health limit school or play & M & M & M & M & M \\
\hline $\begin{array}{l}\text { Physical, emotional, or mental condition requiring: treatment, } \\
\text { medicine, or special equipment }\end{array}$ & M & M & M & M & M \\
\hline Type/duration of limiting health conditions & M & M & M & M & M \\
\hline Accidents/injuries needing medical attention in last 12 months & M & M & M & M & M \\
\hline $\begin{array}{l}\text { Accidents/injuries needing hospitalization since last interview/ } \\
\text { since birth }\end{array}$ & & M & M & M & M \\
\hline Number of illnesses requiring medical attention or treatment & M & M & M & M & M \\
\hline Date of last routine health checkup & M & M & M & M & M \\
\hline Date of last dental checkup/work & M & M & M & M & M \\
\hline Source of health insurance, if any & M & M & M & M & M \\
\hline $\begin{array}{l}\text { Behavioral, emotional, or mental problems; did insurance cover } \\
\text { doctor visit }\end{array}$ & M & M & M & M & M \\
\hline $\begin{array}{l}\text { Any medications or prescription drugs taken to help control } \\
\text { activity/behavior }\end{array}$ & M & M & M & M & M \\
\hline Menarche; age at first menses for female child (and mother) & $\mathrm{M}$ & M & M & M & M \\
\hline Right-/left-handedness & & & & M & M \\
\hline Height and body weight of child & M-I & M-I & M-I & M-I & M-I \\
\hline Healthcare during pregnancy leading to child's birth & M & M & M & M & M \\
\hline Postnatal infant healthcare and feeding & M & M & M & M & M \\
\hline Asthma & & & & & $\mathrm{M} / \mathrm{C}$ \\
\hline
\end{tabular}

$C$ child report, $M$ mother report, $M-I$ mother report or interviewer measurement

In 2006, a series of questions concerning catastrophic events that might adversely affect the health and well-being of respondents, such as death or imprisonment of a close relative, was included in the health section. These questions are a modified version of the catastrophic events series used in the NLSY97 questionnaire. Initially all respondents were asked about any such events that had occurred since they were 10 years old. Beginning in 2008, respondents who had previously answered this series are asked only about events since the date of last interview.

In 2010, several additional questions about healthy behaviors and routine checkups were included, and a health and cognition module for respondents aged 29 and over was added. This module was modeled after the age 29 module from the NLSY97 with some adjustments and additions to also maintain comparability to the health modules in the NLSY79. For 2010 and 2012, this module was asked of all respondents ages 29 and older in order to get baseline information for all Young Adults. Thereafter, it has been asked only of respondents who are 29/30 or
Young Adults who are over that age but have not yet completed the module. In 2012, a series of questions about head injuries, based on questions asked of NLSY79 respondents and described above, was incorporated into the health module.

The NLSY97 also collects information on the general health status of respondents in all rounds; for example, they report their height and weight and also describe how they would characterize their weight (very underweight, slightly underweight, etc.) and if they currently wish to lose or gain or stay at the weight they are. Information on health insurance coverage is collected in various rounds as are questions forming a five-item short version of the Mental Health Inventory (MHI-5), developed by Veit and Ware (1983). Information on various health conditions, medical treatments and visits, and out-of-the-ordinary stressors such as being a victim of a violent crime or being homeless is also collected in various survey rounds. In rounds 13-15, respondents who were 29 years of age answered a special series of health questions as a Health-At-Age-29 health module. These included questions about a family 
history of diseases (including detailed questions about diabetes), parents' mortality, respondents' health limitations (including limitations on moderate activities, climbing stairs, social activities, and productivity), energy level, and mood. Other questions were asked about whether the respondent had had a flu shot, a cholesterol test, diabetes test, pap smear, and blood pressure check at some point during the past 2 years. More information on health-related questions included in the NLSY97 can be found at https://www.nlsinfo. org/content/cohorts/nlsy97/topical-guide/health.

\section{$6 \quad$ Health Research Using the NLSY Surveys}

Considerable health-related research has been undertaken using the three NLSY surveys. In this section I highlight a sample of published studies and focus primarily on studies published since 2000 and those that center on child health. The NLS online bibliography (NLSinfo.org) provides a much more complete list of health focused studies. Of note, however, is the wide range of health topics studied, as well as the diversity of disciplinary backgrounds drawn upon. As the examples below illustrate, the surveys provide a great resource for examining aspects of life course health development.

Returning to Fig. 1, the first set of studies I feature use data from the NLSY79 Child and Young Adult surveys to look at health during childhood and adolescence. For example, Atkins and Matsuba (2008) use maternal ratings of childhood personality for over 1000 5- and 6-year-olds to derive resiliency, undercontrol and overcontrol prototypical profile scores. They then extend their analyses to later in childhood and examine whether childhood personality is associated with the likelihood and the timing of an unintentional injury requiring hospitalization or medical attention before the child turned age 13. Their findings suggest an inverse association between the likelihood of childhood unintentional injury and the overcontrolled prototype score. A recent paper by Cheadle and Goosby (2010) focuses on the complex interplay between childhood health and educational development over the early life course by estimating the relationship between birth weight, cognitive development, and timely high school completion. Their models therefore spanned childhood, adolescence, and early adulthood. Especially notable about this paper is the fact that they were able to adjust for fixed-family characteristics and aspects of the home environment by making use of information from siblings. Among several findings from this study, the authors noted that lower birth weight was associated with decreased cognitive skills at age 5 and marginally significantly slower growth rates into adolescence. They also showed that low birth weight increased the risk of not graduating by age 19. The authors concluded that their pattern of findings painted a multifaceted picture of disadvantage that begins in the womb and extends over the life course.

Reflecting the reality that childhood obesity is a major public health problem in the United States, many studies using the NLSY79 Child data focus on how obesity develops over the life course. For example, Huang and colleagues (Huang et al. 2013) identified developmental trajectories of obesity between ages 6 and 18 and classified four distinct categories: chronically obese, decreasing, increasing, and nonobese. They then studied associations between the various obesity trajectories and a number of risk behaviors and psychosocial health in adolescence. Although obesity trajectories were not found to be associated with greater trends in alcohol use or marijuana use, they did find that youth who became obese between childhood and adolescence had poorer psychosocial health compared to youth who followed other trajectories. Other potential effects of childhood overweight on health development have also been studied. For example, Richard Strauss (Strauss 2000) compared 9- and 10-year-old children who were obese and nonobese to see if they differed on global selfesteem scores. He found no significant difference at these ages between the two groups but by 13-14 years of age, significantly lower levels of self-esteem were observed in obese boys, obese Hispanic girls, and obese white girls compared with their nonobese counterparts. More recently, Averett and Stifel (2010) looked at the effect of obesity on cognitive development and uncovered significant effects when the relationship was examined separately by race and gender. 
Other studies focusing on obesity in childhood and adolescence have incorporated maternal and family data into their analyses by merging data from NLSY79 mothers with data on their children as outlined in Fig. 2. The range of inputs varies considerably from breastfeeding versus bottle-feeding ( $\mathrm{Li}$ et al. 2005; Salsberry and Reagan 2005; Seipel and Shafer 2013), food choices offered to young children (Faith et al. 2003), family income (Chia 2013), parental marital disruption and divorce (Arkes 2012), maternal prenatal behaviors such as smoking (Huang et al. 2014; Li et al. 2003; Salsberry and Reagan 2005, 2007; Seipel and Shafer 2013), maternal prepregnancy weight (Li et al. 2005; Salsberry and Reagan 2005, 2007), weight gain during pregnancy (Seipel and Shafer 2013), and other background factors such as parental engagement in children's daily activities, maternal age, and maternal education (Huang et al. 2014).

The relationship between various aspects of maternal employment and children's obesity has also gained attention. In a 2003 publication, Anderson, Butcher, and Levine suggest that increasing child obesity might be related to an increase in mothers working outside the home and posit that working mothers may not have time to prepare nutritious low-calorie meals and supervise their children's outdoor play that tends to expend calories. Using data on siblings to hold constant all of the family characteristics that might be correlated both with children's weight and mothers' hours worked, study results indicated that although children were more likely to be overweight if their mothers worked more hours per week over the child's life, it was higher socioeconomic status mothers whose work intensity was particularly deleterious for their children's overweight status. Others have also examined the relationship between maternal work hours and child obesity and found longer hours worked to be positively related to children's overweight (Courtemanche 2009; Liu et al. 2009). Other studies have found a more nuanced relationship, however. For example, Miller (2011) found that the timing of maternal work during a child's life mattered to the relationship and that effects of maternal work were confined to relatively low income families and to children who grew up with single mothers. Stewart et al. (2012) also found that unemployment events and the type of support that a mother received during unemployment spells were related to changes in children's weight.

Additional studies have examined various parental and family background influences on a range of child health development outcomes aside from child obesity. Some of these include how income and family structure impact routine medical and dental care provision for children (Berger 2004), the association between unwanted pregnancy and prenatal and postpartum maternal behaviors that adversely affect infant and child health (Joyce et al. 2000), the relationship between dark and cluttered home environments and the incidence of home injuries among children (Mott 1999), the distance between a child's home and a hospital and the probability of utilizing preventive care (Currie and Reagan 2003), length of maternity leave and children's immunizations (Berger et al. 2005), the effects of breastfeeding on long-term child health and well-being (Colen and Ramey 2014), various measures of economic disadvantage on intrauterine growth restriction (Reagan et al. 2007), household income histories, and changes in child depression levels (Strohschein 2005). Finally, a recent paper by Wolfe (2015) unpacked the components of socioeconomic status and found that children's health was more vulnerable to their families' wealth whereas adolescents' health was more sensitive to the current income of their families.

This brief and selected review of past studies provides a glimpse of the ways the NLSY data can be used to explore important aspects of life course health development. As the maternal and child health research community continues to explore how health develops across the life course, the NLSY can continue to be a rich source of data to answer important research questions.

\section{$7 \quad$ Obtaining and Using NLSY Data}

The NLSY public datasets (along with the data from the Original Cohorts) can be accessed free of charge through the NLS Investigator (www. nlsinfo.org/investigator), the data retrieval sys- 
tem used for obtaining public NLS data. In NLS Investigator, cohort-specific datasets can be searched by Area of Interest, Word in Title, Question Text, Question Name, Reference Number, and Survey Year. Also available at www.nlsinfo.org are cohort-specific Users Guides with an introduction to each sample, information on how to use and understand the data, topical guides, tutorials on various topics such as how to merge the NLSY79 Mother and Child data, and questionnaires for all rounds. Data can be downloaded into SAS, STATA, SPSS, and R. In addition to the public data, geocode data variables are available on a restricted basis: researchers interested in using the restricted data must complete an accessing agreement and be approved. Users with questions may also contact NLS User Services at usersvc@chrr.osu.edu for assistance with data use.

\section{References}

Anderson, P., Butcher, K., \& Levine, P. (2003). Economic perspectives on childhood obesity. Economic Perspectives, 27(3), 30-49.

Arkes, J. (2012). Longitudinal association between marital disruption and child BMI and obesity. Obesity, 20(8), 1696-1702.

Atkins, R., \& Matsuba, M. K. (2008). Association of personality and the likelihood of serious unintentional injury during childhood. Journal of Pediatric Nursing, 23(6), 451-459.

Averett, S., \& Stifel, D. (2010). Race and gender differences in the cognitive effects of childhood overweight. Applied Economics Letters, 17(17), 1673-1679.

Berger, L. (2004). Income, family structure, and child maltreatment risk. Children and Youth Services Review, 26(8), 725-799.

Berger, L., Hill, J., \& Waldfogel, J. (2005). Maternity leave, early maternal employment and child health and development in the US. Economic Journal, 115(501), F29-F47.

Bumpass, L., \& Sweet, J. (1989). National estimates of cohabitation. Demography, 26(4), 615-625.

Bumpass, L., \& Lu, H. (2000). Trends in cohabitation and implications for children's family contexts in the United States. Population Studies, 54, 29-41.

Caldwell, B., \& Bradley, R. (1984). Home observation for measurement of the environment. Little Rock: University of Arkansas at Little Rock, Center for Child Development and Education.

Cheadle, J., \& Goosby, B. (2010). Birth weight, cognitive development, and life chances: A comparison of siblings from childhood into early adulthood. Social Science Research, 39(4), 570-584.

Chia, Y. F. (2013). Dollars and pounds: The impact of family income on childhood weight. Applied Economics, 45(14), 1931-1941.

Colen, C., \& Ramey, D. (2014). Is breast truly best? Estimating the effects of breastfeeding on long-term child health and wellbeing in the United States using sibling comparisons. Social Science and Medicine, 109, 55-65.

Courtemanche, C. (2009). Longer hours and larger waistlines? The relationship between work hours and obesity. Forum for Health Economics and Policy, 12(2). doi:10.2202/1558-9544.1123.

Currie, J., \& Reagan, P. (2003). Distance to hospital and children's use of preventive care: Is being closer better, and for whom? Economic Inquiry, 41(3), 378-392.

D’Onofrio, B., Goodnight, J., Van Hulle, C., Rodgers, J., Rathouz, P., Waldman, I., \& Lahey, B. (2009a). A quasi-experimental analysis of the association between family income and offspring conduct problems. Journal of Abnormal Child Psychology, 37(3), 415-429.

D’Onofrio, B., Goodnight, J., Van Hulle, C., Rodgers, J., Rathouz, P., Waldman, I., \& Lahey, B. (2009b). Maternal age at childbirth and offspring disruptive behaviors: Testing the causal hypothesis. Journal of Child Psychology and Psychiatry, 50(8), 1018-1028.

D’Onofrio, B., Van Hulle, C., Waldman, I., Rodgers, J., Harden, K. P., Rathouz, P., \& Lahey, B. (2008). Smoking during pregnancy and offspring externalizing problems: An exploration of genetic and environmental confounds. Development and Psychopathology, 20(1), 139-164.

Donahue, K., Van Hulle, C., Rodgers, J., \& D’Onofrio, B. (2014). Psychosocial predictors of adolescent sexual risk behavior: A quasi-experimental analysis in a nationally representative sample of american youths. Journal of Adolescent Health, 54(2), S15-S16.

Dunn, L., \& Dunn, L. (1981). PPVT-R revised manual. Circle Pines, Minnesota: American Guidance Service, Inc..

Faith, M., Heshka, S., Keller, K., Sherry, B., Matz, P., Pietrobelli, A., \& Allison, D. (2003). Maternal-child feeding patterns and child body weight: Findings from a population-based sample. Archives of Pediatrics and Adolescent Medicine, 157(9), 926-932.

Goodnight, J., Lahey, B., Van Hulle, C., Rodgers, J., Rathouz, P., Waldman, I., \& D’Onofrio, B. (2012). A quasi-experimental analysis of the influence of neighborhood disadvantage on child and adolescent conduct problems. Journal of Abnormal Psychology, 121(1), 95-108.

Harter, S. (1985). Manual for the self-perception profile for children. Denver, Colorado: University of Denver.

Hayward, M., \& Gorman, B. (2004). The long arm of childhood: The influence of early-life social conditions on men's mortality. Demography, 41(1), 87-108.

Huang, D., Lanza, H. I., Wright-Volel, K., \& Anglin, M. D. (2013). Developmental trajectories of childhood 
obesity and risk behaviors in adolescence. Journal of Adolescence, 36(1), 139-148.

Huang, D., Lanza, H. I., \& Anglin, M. D. (2014). Trajectory of adolescent obesity: Exploring the impact of prenatal to childhood experiences. Journal of Child and Family Studies, 23(6), 1090-1101.

Jaffee, S., Van Hulle, C., \& Rodgers, J. (2011). Effects of nonmaternal care in the first 3 years on children's academic skills and behavioral functioning in childhood and early adolescence: A sibling comparison study. Child Development, 82(4), 1076-1091.

Joyce, T., Kaestner, R., \& Korenman, S. (2000). The effect of pregnancy intention on child development. Demography, 37(1), 83-94.

Kennedy, S., \& Bumpass, L. (2008). Cohabitation and children's living arrangements: New estimates from the United States. Demographic Research, 19, 16631692. doi:10.4054/DemRes.2008.19.47.

Li, C., Mayo, M. S., \& Ahluwalia, J. (2003). Maternal smoking during pregnancy, birth weight, and childhood overweight: A suppression effect model. Annals of Epidemiology, 13(8), 569.

Li, C., Kaur, H., Choi, W., Huang, T., Lee, R., \& Ahluwalia, J. S. (2005). Additive interactions of maternal prepregnancy BMI and breast-feeding on childhood overweight. Obesity Research, 13(2), 362-371.

Liu, E., Cheng, H., Matsumoto, T., \& Chou, S. (2009). Maternal full-time employment and overweight children: Parametric, semi-parametric, and non-parametric assessment. Journal of Econometrics, 152(1), 61-69.

Manning, W. D., \& Smock, P. (2005). Measuring and modeling cohabitation: New perspectives from qualitative data. Journal of Marriage and the Family, 67(4), 989-1002.

Mendle, J., Harden, K. P., Turkheimer, E., Van Hulle, C., D’Onofrio, B., Brooks-Gunn, J., Rodgers, J., Emery, R., \& Lahey, B. (2009). Associations between father absence and age of first sexual intercourse. Child Development, 80(5), 1463-1480.

Miller, D. (2011). Maternal work and child overweight and obesity: The importance of timing. Journal of Family and Economic Issues, 32(2), 204-218.

Mott, J. (1999). Personal and family predictors of children's medically attended injuries that occurred in the home. Injury Prevention, 5(3), 189-193.
Reagan, P., Salsberry, P., \& Olsen, R. (2007). Does the measure of economic disadvantage matter? Exploring the effect of individual and relative deprivation on intrauterine growth restriction. Social Science and Medicine, 64(10), 2016-2029.

Rodgers, J., Bard, D., Johnson, A., D’Onofrio, B., \& Miller, W. (2008). The cross-generational motherdaughter-aunt-niece design: Establishing validity of the MDAN design with NLSY fertility variables. Behavior Genetics, 38(6), 567-578.

Salsberry, P., \& Reagan, P. (2005). Dynamics of early childhood overweight. Pediatrics, 116(6), 1329-1338.

Salsberry, P., \& Reagan, P. (2007). Taking the long view: The prenatal environment and early adolescent overweight. Research in Nursing and Health, 30(3), 297-307.

Seipel, M., \& Shafer, K. (2013). The effect of prenatal and postnatal care on childhood obesity. Social Work, 58(3), 241-252.

Stewart, L., Liu, Y., \& Rodriguez, E. (2012). Maternal unemployment and childhood overweight: Is there a relationship? Journal of Epidemiology and Community Health, 66(7), 641-646.

Strauss, R. (2000). Childhood obesity and self-esteem. Pediatrics, 105(1), N1-N5.

Strohschein, L. (2005). Household income histories and child mental health trajectories. Journal of Health and Social Behavior, 46(4), 359-375.

Veit, C., \& Ware, J. (1983). The structure of psychological distress and well-being in general populations. Journal of Consulting and Clinical Psychology, 51(5), $730-742$.

Ware, J., Jr., Kosinski, M., \& Keller, S. (1995). SF-12: How to score the SF-12 physical and mental health summary scales. New England Medical Center, Boston, MA: The Health Institute.

Wechsler, D. (1974). Wechsler intelligence scale for children-revised. New York: Psychological Corporation.

Wolfe, J. (2015). The effects of socioeconomic status on child and adolescent physical health: An organization and systematic comparison of measures. Social Indicators Research, 123(1), 39-58.

Open Access This chapter is licensed under the terms of the Creative Commons Attribution 4.0 International License (http://creativecommons.org/licenses/by/4.0/), which permits use, sharing, adaptation, distribution and reproduction in any medium or format, as long as you give appropriate credit to the original author(s) and the source, provide a link to the Creative Commons license and indicate if changes were made.

The images or other third party material in this chapter are included in the chapter's Creative Commons license, unless indicated otherwise in a credit line to the material. If material is not included in the chapter's Creative Commons license and your intended use is not permitted by statutory regulation or exceeds the permitted use, you will need to obtain permission directly from the copyright holder. 